\title{
Retinoid-dependent growth inhibition, differentiation and apoptosis in acute promyelocytic leukemia cells. Expression and activation of caspases
}

\author{
M Gianni ${ }^{1,4}$, I Ponzanelli ${ }^{1,4}$, L Mologni ${ }^{1}$, U Reichert ${ }^{3}$, \\ A Rambaldi ${ }^{2}, M^{2}$ Terao ${ }^{1}$ and E Garattini ${ }^{*, 1}$ \\ ${ }^{1}$ Laboratory of Molecular Biology, Centro Catullo e Daniela Borgomainerio \\ Istituto di Ricerche Farmacologiche "Mario Negri", via Eritrea, 62. 20157 \\ Milano, Italy \\ 2 Divisione di Ematologia, Ospedali Riuniti di Bergamo, Largo Barozzi, 1. 24100 \\ Bergamo, Italy \\ ${ }^{3}$ CIRD-Galderma Research and Development, Sophia Antipolis, France \\ 4 These two authors contributed equally to the data presented in this study \\ * Corresponding author: E Garattini, Laboratory of Molecular Biology, Centro \\ Catullo e Daniela Borgomainerio, Istituto di Ricerche Farmacologiche "Mario \\ Negri", via Eritrea, 62. 20157 Milano, Italy. Tel: +390239014533; Fax: \\ +39023546277; E-mail: egarattini@irfmn.mnegri.it
}

Received 22.10.99; revised 14.1.00; accepted 2.2.00

Edited by L Fesus

\begin{abstract}
In the NB4 model of acute promyelocytic leukemia (APL), ATRA, 9-cis retinoic acid (9-cis RA), the pan-RAR and RAR $\alpha$ selective agonists, TTNPB and AM580, induce growth inhibition, granulocytic differentiation and apoptosis. By contrast, two RXR agonists, a RAR $\beta$ agonist and an anti-AP1 retinoid have very limited activity, ATRA- and AM580dependent effects are completely inhibited by RAR antagonistic blockade, while 9-cis RA-induced cell-growth-inhibition and apoptosis are equally inhibited by RAR and RXR antagonists. ATRA, 9-cis RA and AM580 cause upregulation of the mRNAs coding for pro-caspase-1, -7, -8 , and -9 , which, however, results in increased synthesis of only pro-caspase-1 and -7 proteins. These phenomena are associated with activation of pro-caspase- $6,-7$ and -8 , cytochrome $c$ release from the mitochondria, inversion of $\mathrm{Bcl}-2 / \mathrm{Bax}$ ratio and degradation of PML-RAR $\alpha$. Caspase activation is fundamental for retinoid-induced apoptosis, which is suppressed by the caspase-inhibitor Z-VAD. Cell Death and Differentiation(2000) 7, $447-460$.
\end{abstract}

Keywords: APL; caspase; ATRA; retinoids

Abbreviations: APL, acute promyelocytic leukemia; ATRA, alltrans retinoic acid; cyt $c$, cytochrome $c$; 9-cis $\mathrm{RA}, 9$-cis retinoic acid

\section{Introduction}

All-trans retinoic acid is a powerful cyto-differentiating agent. $^{1}$ The compound is successfully used in the

The words apoptosis and programmed cell death (PCD) are used interchangeably throughout the article treatment of acute promyelocytic leukemia $(\mathrm{APL}),{ }^{2}$ a rare form of acute myelogenous leukemia in the adult. ${ }^{3,4}$ Treatment of the vast majority of APL patients with a single course of ATRA results in complete clinical remission. ${ }^{2}$ This is the consequence of a retinoiddependent granulocytic maturation effect, which overcomes the promyelocytic differentiation block observed in the leukemic clone. ${ }^{2}$ At present the modalities by which ATRA-differentiated leukemic cells are eliminated in vivo are not known. It is generally assumed that ATRA causes maturation of leukemic promyelocytes into cells resembling terminally differentiated granulocytes, which have a limited lifespan and are bound to undergo spontaneous apoptosis. ${ }^{1}$ Freshly isolated APL cells undergo granulocytic maturation upon treatment with ATRA in vitro, however, the process of apoptosis and the underlying mechanisms have been the object of only a few studies. $^{5-8}$ In particular, the relationship between growth arrest, cytodifferentiation and apoptosis are not well known. In HL-60, a PML-RAR $\alpha$ negative pro-myeloblastic cell line undergoing granulocytic maturation upon in vitro challenge with ATRA $^{9}$ and receptor selective retinoids, ${ }^{10}$ retinoid-dependent differentiation and apoptosis are two independent processes. ${ }^{11}$ Differentiation is mainly regulated through retinoic acid receptors of the RAR type, whereas apoptosis is dependent on RXR activation. ${ }^{11}$ However, it is not known whether the results obtained in the HL-60 cellular model can be transferred to the APL situation, as the cell line does not have the typical $t(15: 17)$ chromosomal translocation and does not express PML-RAR $\alpha$. Lack of PML-RAR $\alpha$ expression is particularly relevant given the influence that this protein has on the processes of granulocytic maturation and apoptosis. ${ }^{12}$

Caspases are a family of cysteine proteases cleaving substrate proteins at the carboxyl terminus of an Asp residue. $^{13,14}$ The family consists of at least 13 members, which are characterized by a varying degree of primary structure similarity. ${ }^{15}$ These proteases are normally present inside the cell under the form of an inactive precursor, which can be activated upon selective proteolytic cleavage. ${ }^{16}$ Cleavage can be the result of an autocatalytic process or can be triggered by two or more caspases acting sequentially in a cascade fashion. Different caspase isoenzymes are involved in the commitment and effector phase of the apoptotic process triggered by various stimuli in different cellular contexts. ${ }^{17}$ For instance, activation of death receptors by FAS ligand activates caspase-8, ${ }^{18}$ which, in turn, directly, or indirectly through cytochrome $c$ (cyt $c$ ) release from the mitochondria, ${ }^{19,20}$ leads to the activation of caspase- 3 and caspase-3-like activities (which include caspase-6 and -7). These last caspases are ultimately responsible for 
the demise of cells. The influence of ATRA and other retinoids on the level of expression and on the state of activation of the various isoenzymes constituting the caspase family is still largely obscure. In addition and more specifically, it is not known whether caspases are involved in the apoptogenic program triggered by ATRA and other retinoids in APL cells, although these proteases have been very recently implicated in the degradation of the PML-RAR $\alpha$ protein. ${ }^{21,22}$

In this study, the growth inhibitory, cyto-differentiating and apoptogenic activities of ATRA, 9-cis RA and other synthetic retinoids in the NB4 model of APL are compared. In addition, the influence of the antagonistic blockade of the RAR and RXR nuclear retinoic acid receptors on the same retinoid-dependent phenomena is studied. Furthermore, we describe the profile of induction and activation of various members of the caspase family, demonstrating that activation of these proteases is involved in the process of retinoid-induced apoptosis of APL cells. Finally, we document that retinoid-dependent caspase activation is associated with cyt $c$ leakage from the mitochondria and this effect is paralleled by an alteration in the ratio of pro-apoptotic Bax to the anti-apoptotic Bcl-2 proteins.

\section{Results}

\section{Growth inhibition, granulocytic maturation and apoptosis following treatment of NB4 cells with ATRA and synthetic retinoids}

Challenge of NB4 cells with a cyto-differentiating concentration of ATRA $\left(10^{-6} \mathrm{M}\right)$ results in growth arrest, which starts to be evident following 4 days of treatment (Figure 1A). Growth arrest is paralleled by granulocytic maturation, as illustrated by the increase in PMA-stimulated NBT-reducing activity (Figure 1B). Maximal cyto-differentiation is observed at 4 days, a time at which more than $80 \%$ of the cells have morphological signs of granulocytic maturation (data not shown). From the fourth day on, NB4 cells cultured in the presence of ATRA show a progressive decrease in cell viability (Figure $1 \mathrm{C}$ ). This effect is predominantly the consequence of programmed cell death (PCD), as indicated
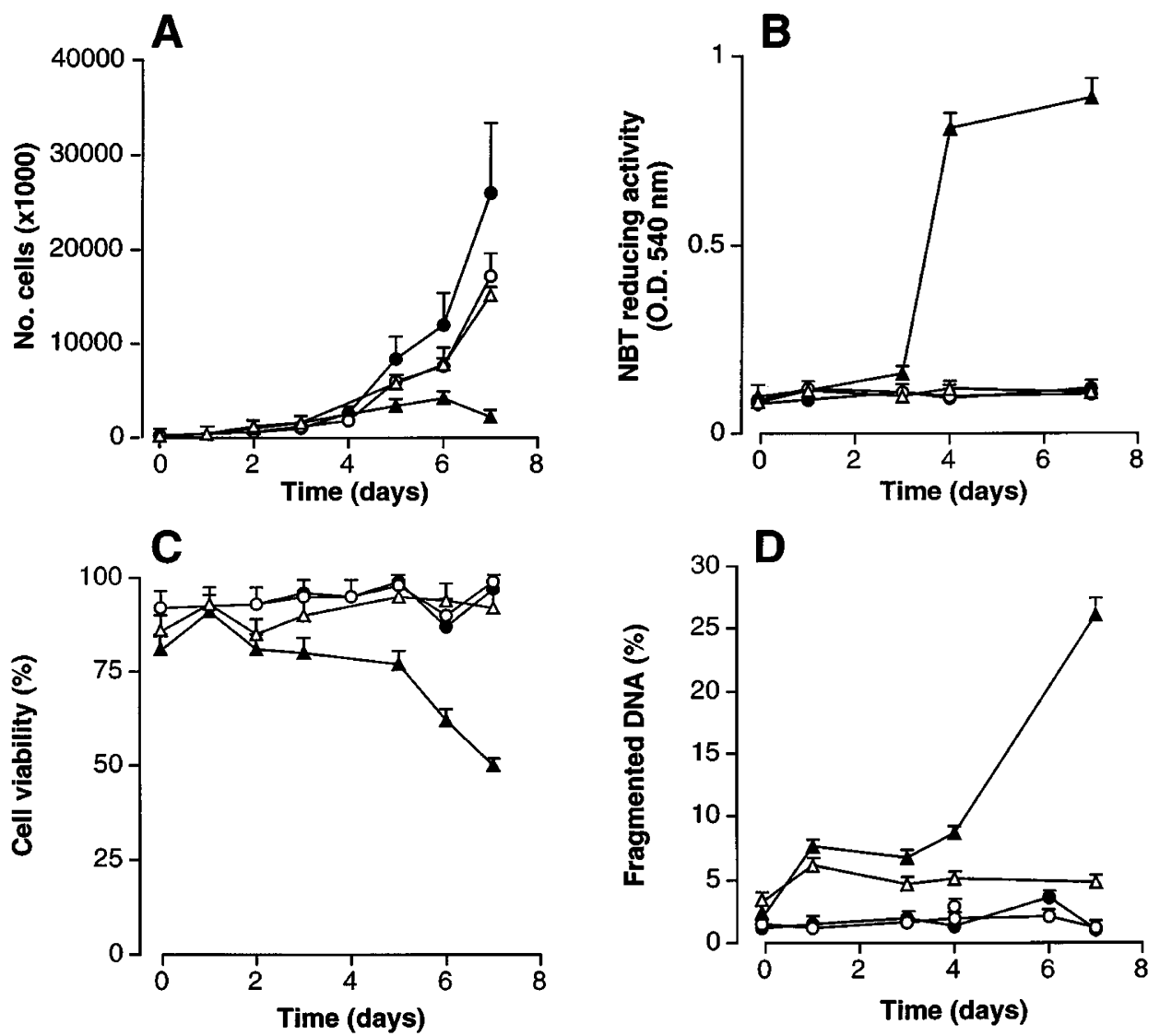

Figure 1 Effect of ATRA on growth, granulocytic maturation, viability and DNA fragmentation in retinoic acid-sensitive NB4 and retinoic acid-resistant NB4.306 cells. NB4 (solid symbols) or NB4.306 cells (open symbols) were seeded at an initial concentration of $2 \times 10^{5} / \mathrm{ml}$ and were treated for the indicated amount of time with medium alone (circles) or medium containing ATRA $\left(10^{-6} \mathrm{M}\right)$ (triangles). Aliquots of the cultures were withdrawn at each time-point and subjected to counting following erythrosin staining for the determination of the total number of viable cells $(\mathbf{A})$, the percentage of viable cells (B), the level of granulocytic maturation, as assessed by measuring NBT-reducing activity (C), and the degree of apoptosis, as assessed by measuring DNA fragmentation with the diphenylamine assay (D). Results are the mean \pm S.D. of three separate culture dishes 
by an increase in the number of cells showing signs of morphological apoptosis following staining with DAPI (see Figure 2C). Apoptotic morphology is characterized by condensation and fragmentation of the nucleus, reduced cell size as well as increased DNA fragmentation, which is revealed by the quantitative diphenylamine (DFA) assay (Figure 1D) and by agarose gel electrophoresis of nucleosomal DNA (data not shown). A linear increase in the amount of fragmented DNA is observed between the fourth and seventh day, which correlates with the kinetics of cell loss from the culture. Cell growth arrest, cyto-differentiation, apoptosis and eventually cell demise are likely to be dependent on PMLRAR $\alpha$ activation as challenge of the ATRA-resistant and PML$\mathrm{RAR} \alpha$-defective NB4 cell clone, NB4.306 ${ }^{23}$ with the retinoid, does not result in any of these events (Figure 1).

ATRA is known to activate all forms of RARs ${ }^{24}$ and it is potentially converted into 9-cis $R A$, a strong $R X R$ agonist. $^{25}$ In addition, NB4 cells express PML-RAR $\alpha$, $\mathrm{RAR} \alpha, \mathrm{RXR} \alpha$ and $\mathrm{RXR} \beta$ in basal conditions as well as RAR $\beta$ upon challenge with ATRA. ${ }^{26}$ For these reasons, we first compared the effects of 9-cis RA [pan-RAR and pan-RXR agonist], ${ }^{25}$ TTNPB [pan-RAR agonist], ${ }^{27}$ AM580 [selective $\mathrm{RAR} \alpha$ agonist], ${ }^{10}$ CD2019 [selective RAR $\beta$ agonist], ${ }^{28}$ CD2915 and CD2809 [RXR agonists] ${ }^{29}$ as well as CD2409 [anti-AP1 retinoid] to those of ATRA, using two different concentrations $\left(10^{-6}\right.$ and $\left.10^{-8} \mathrm{M}\right)$ of each retinoid. We did not take into consideration agonists of $\operatorname{RAR} \gamma$, since this type of receptor is not expressed in undifferentiated or ATRA-differentiated NB4 cells. ${ }^{26}$ The binding characteristics of all these retinoids are summarized in Table 1. At both concentrations, ATRA, 9-cis RA, TTNPB and AM580 strongly inhibit the growth of NB4 cells (Figure 2A). For AM580, ATRA and 9-cis RA, we conducted more detailed concentration-course experiments, determining almost identical growth inhibitory $\mathrm{EC}_{50} \mathrm{~S}$ of $1.8 \times 10^{-9}, 2.9 \times 10^{-9}$ and $3.9 \times 10^{-9} \mathrm{M}$, respectively. At $10^{-8} \mathrm{M}, \mathrm{CD} 2019, \mathrm{CD} 2915, \mathrm{CD} 2809$ and CD2409 have only minor effects on cell proliferation (Figure 2A). By contrast, at $10^{-6} \mathrm{M}$, only CD2019 and CD2915 have a strong growth inhibitory action, though this does not correlate with the binding affinity or transactivation potential of the two ligands for the correspond-

Table 1. Binding constants of the retinoids used in the study

\begin{tabular}{lrrrr}
\hline Compound & RAR $\alpha$ & KA (nM) & & \\
\hline AM580 & 0 & 74 & 450 & N.B. \\
CD2019 & 1100 & 34 & 160 & N.B. \\
CD2809 & 6130 & 1700 & 5200 & 540 \\
CD2915 & 9700 & 10000 & 3220 & 805 \\
CD2409 & 8200 & 3480 & 6770 & N.B. \\
CD3106 & 9 & 10 & 4 & N.B. \\
CD3159 & 725 & 408 & 1460 & 16 \\
ATRA & 19 & 4 & 2 & 730 \\
9-CisRA & 45 & 11 & 24 & 50 \\
TTNPB & 22 & 3 & 5 & N.B. \\
\hline
\end{tabular}

The binding constants for the various retinoids on the different isotypes of RAR or RXR were determined by direct or competition binding experiments using human nuclear retinoic acid receptors. The values are representative of several experiments performed on each compound. N.B.=no significant binding ing receptors. As to cyto-differentiation, AM580 and TTNPB are far more active than ATRA or 9-cis RA in inducing granulocytic maturation of NB4 cells, causing maximal increase in PMA-stimulated NBT-reducing activity at both $10^{-8}$ and $10^{-6} \mathrm{M}$ (Figure 2B). At $10^{-8} \mathrm{M}$, TTNPB and AM580 induce a 3 - and 1.5-fold higher NBT-reducing activity than the maximally effective concentrations $\left(10^{-6}\right)$ of ATRA or 9-cis RA. In line with these results, calculated $E_{50}$ s values for AM580, ATRA

A

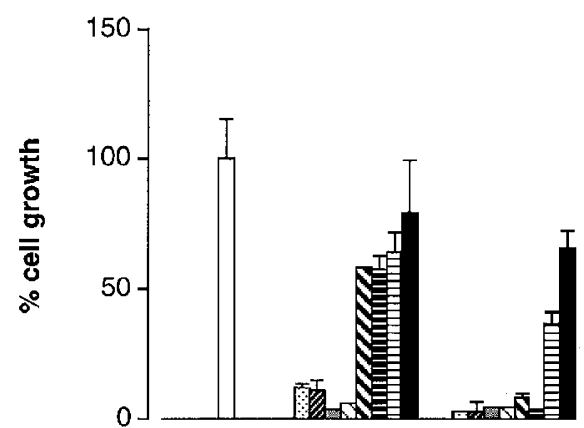

B

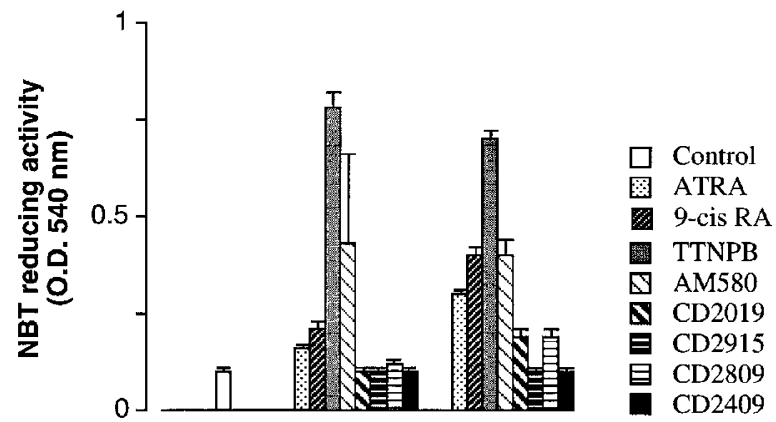

C

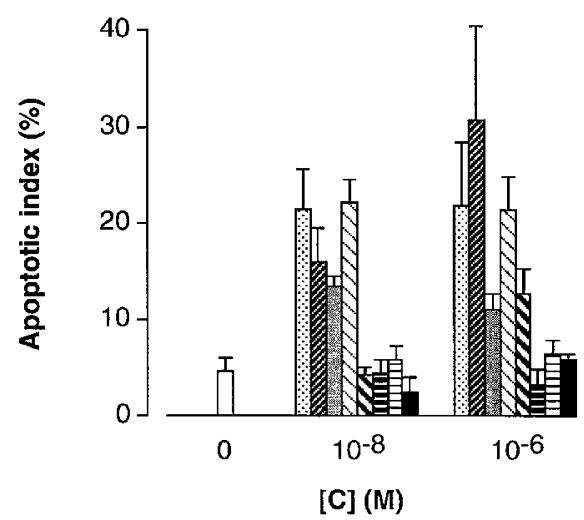

Figure 2 Effect of ATRA and other retinoids on growth, granulocytic maturation, and apoptosis in NB4 cells. NB4 cells were seeded at an initial concentration of $2 \times 10^{5} / \mathrm{ml}$ and treated for 6 days with medium alone (open bars) or medium containing the indicated concentration of ATRA, 9-cis RA, TTNPB, AM580, CD2019, CD2915, CD2809 and CD2409. Aliquots of the cultures were withdrawn and subjected to counting following erythrosin staining for the determination of the total number of viable cells $(\mathbf{A})$, the level of NBT-reducing activity (B), and the degree of apoptosis, following staining with DAPI (C). Results are the mean \pm S.D. of three separate culture dishes and are representative of at least three independent experiments conducted with each compound 
and 9 -cis RA were $1.3 \times 10^{-9}, 2.9 \times 10^{-7}$ and $1 \times 10^{-7} \mathrm{M}$, respectively.

As shown in Figure 2C, compounds like CD2915, CD2809, CD2409 and CD2019, which have no or marginal cyto-differentiating activity are also largely ineffective in inducing programmed cell death (PCD) in NB4 cells. However, the process of retinoid-induced PCD does not appear to be a simple consequence of the processes of growth arrest and granulocytic maturation. In fact, at both $10^{-8}$ and $10^{-6} \mathrm{M}$, ATRA and 9-cis RA are as effective as or more effective than the strong cytodifferentiating agents, TTNPB and AM580, in inducing apoptosis. This does not correlate with the relative antiproliferative and cyto-differentiating potency of the four retinoids. The phenomenon was investigated more thoroughly in the case of ATRA, AM580 and 9-cis RA, for which we calculated $E_{50}$ s of $1.5 \times 10^{-9}, 5.9 \times 10^{-10}$ and $1.4 \times 10^{-8}$, respectively.

\section{Effects of RAR and RXR agonists and antagonists on retinoid-induced growth arrest, granulocytic maturation and apoptosis}

Activation of PML-RAR $\alpha$ and/or RAR $\alpha$ is crucial for the pharmacological effects of ATRA, 9-cis RA and AM580 in NB4 cells. At an optimal 100:1 molar ratio, CD3106 completely reverses the proliferation arrest (Figure $3 A$ ) and blocks the increase in NBT-reducing activity (Figure $3 B$ ) observed in the presence of ATRA $\left(10^{-7} \mathrm{M}\right)$. Moreover, the compound inhibits the apoptotic process triggered by the natural retinoid (Figure $3 \mathrm{C}$ ), eventually resulting in a lack of viable cell loss (data not shown). The inhibitory effect of the antagonist on the three parameters considered is concentration-dependent and is substantially lower (data not shown) at a 10:1 molar ratio of CD3106/ATRA. Similarly, CD3106 inhibits the growth arrest, granulocytic maturation and apoptosis induced by treatment with AM580 and 9-cis RA (data not shown).

RXR activation can play a significant, albeit complex, role in the process of retinoid-induced apoptosis, as indicated by experiments performed with RXR antagonists and combinations of RAR and RXR agonists. At a 100:1 molar ratio relative to the two natural retinoids, the $R X R$ antagonist CD $3159^{30}$ does not have any appreciable effect on the growth arrest induced by ATRA, whereas it inhibits by approximately $50 \%$ the anti-proliferative action of 9 -cis RA (Figure 3D). At both 10:1 and 100:1 molar ratio, CD3159 lowers by approximately $20 \%$ the induction of NBT-reducing activity caused by 9 -cis RA, while exerting only marginal effects on the ATRA-dependent elevation of the same enzymatic activity (Figure $3 \mathrm{E}$ ). The selective inhibitory action of CD3159 $\left(10^{-5} \mathrm{M}\right)$ on 9-cis RA is most striking in the case of the apoptogenic process triggered by the natural retinoid in NB4 cells (Figure 3F). In fact, 9-cis RA-triggered PCD (as assessed by scoring the number of fragmented nuclei by DAPI (Figure 3F, left panel) or by measuring plasma membrane phosphatidylserine externalization (right panel) is completely blunted by the RXRantagonist at the concentration of $10^{-5} \mathrm{M}$. Interestingly, the general lack of effect of CD3159 on ATRA activity indicates that conversion of the retinoid to 9-cis RA in NB4 cells is either not taking place or is of minor quantitative importance.

As expected, AM580 $\left(10^{-8} \mathrm{M}\right)$ alone has a large effect on cell proliferation (Figure 4A), NBT-reducing activity (Figure 4B) and the number of cells showing signs of apoptosis (Figure 4C), whereas treatment of NB4 cells with each RXR agonist $\left(10^{-6} \mathrm{M}\right)$ alone does not significantly affect the three parameters. Addition of CD2915 or CD2809 to AM580 has no major influence on the growth inhibitory or cyto-differentiating activity of the PML-RAR $\alpha /$ RAR $\alpha$ agonist. However, CD2915 and CD2809 interact synergistically with AM580 and enhance its apoptogenic effects on NB4 cells. Thus, maximally effective cyto-differentiating and growth-inhibitory concentrations of AM580 induce only sub-optimal apoptogenic effects, which can be enhanced by addition of RXR agonists.

\section{Influence of ATRA and other cyto-differentiating retinoids on the expression of caspase proteins and transcripts in NB4 cells}

To determine which members of the caspase family ${ }^{13,14}$ are expressed in NB4 cells grown under basal conditions and to evaluate the effect of ATRA and other cyto-differentiating retinoids on the level of these proteins, we performed Western blot experiments with isoform-specific antibodies (Figure 5A, left panels). Undifferentiated NB4 cells express the precursor form of all the caspase isoenzymes which we took into consideration (caspase-4 included, data not shown). Upon treatment with cyto-differentiating concentrations of ATRA $\left(10^{-6} \mathrm{M}\right)$, induction of pro-caspase- 1 and pro-caspase-7 is evident, whereas all the other caspase pro-forms do not appear to be modulated by the retinoid. The increase in pro-caspase-7 precedes that of procaspase-1, being already evident at $6 \mathrm{~h}$ and maximal at $48 \mathrm{~h}$. Induction of pro-caspase-1 and pro-caspase-7 is relatively selective, given the lack of ATRA-dependent regulation of $\beta$-actin, which was used as a control for all the Western blot experiments. ATRA-induced variations in caspase levels are not observed in the retinoid-resistant NB4.306 cellular clone (Figure 5A, right panels). In this cell type, the pattern of basal caspase expression is the same as that observed in the parental cell line, as demonstrated for pro-caspase-1, $-2,-3,-6$ and 10. As shown in Figure 5B, treatment of NB4 cells for 4 days with maximal cytodifferentiating and apoptotic concentrations of ATRA $\left(10^{-6} \mathrm{M}\right)$, 9-cis RA $\left(10^{-6} \mathrm{M}\right)$ and AM580 $\left(10^{-8} \mathrm{M}\right)$ results in a similar induction of pro-caspase-1 and -7, leaving unaffected pro-caspase-3 and -8. Thus, in spite of differences in the type(s) of nuclear retinoic acid receptors activated, the processes of cyto-differentiation and/or apoptosis triggered by the three retinoids eventually result in a similar profile of caspase induction. In various experiments, the ATRA-dependent induction of pro-caspase-7 is accompanied by the progressive appearance of increasing amounts of the $29 \mathrm{kDa}$ proteolytic fragment, which is readily evident at the $96 \mathrm{~h}$ points (Figure $5 \mathrm{~A}$, left panel). This fragment has the same apparent molecular 
weight of the large subunit of activated caspase- 7 and its appearance can be blocked by treatment with the general caspase inhibitor z-VAD (data not shown). By contrast, ATRA treatment does not cause the appearance of proteolytic degradation bands consistent with the conversion of any other of the pro-caspase isoenzymes into the corresponding catalytically active forms. This is particularly surprising in the case of pro-caspase-3 and -9. Although we cannot rule out a low level of sensitivity of the Western blot assay, the lack of caspase- 3 and -9 degradation bands is not due to the intrinsic characteristics of the antibodies used, as the same reagents allowed the identification of
A
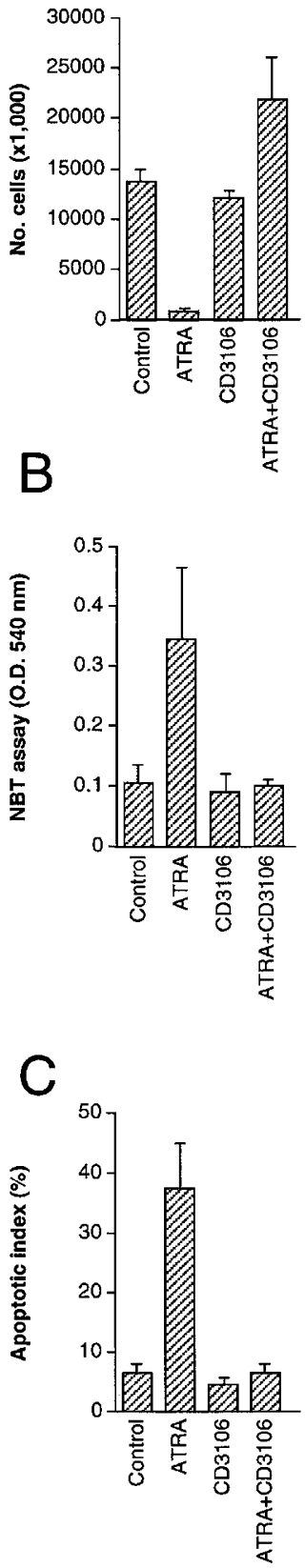
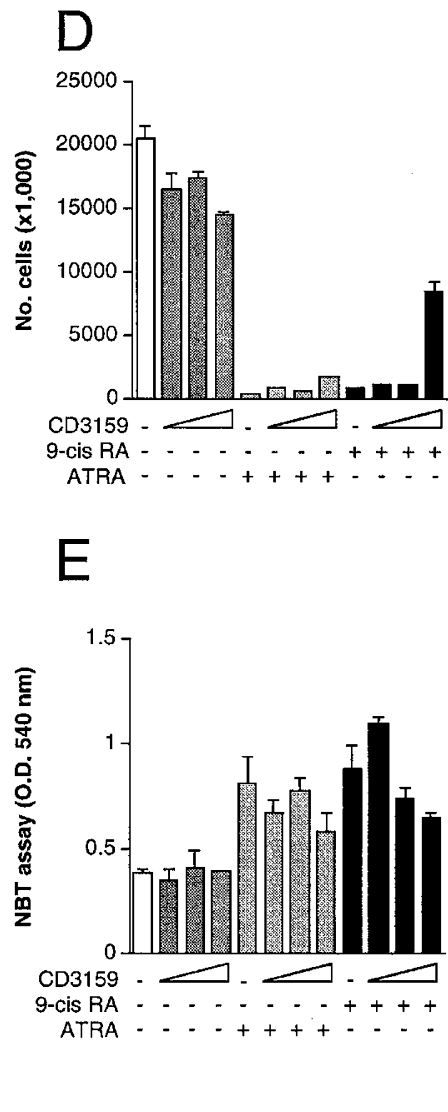

$\mathrm{F}$

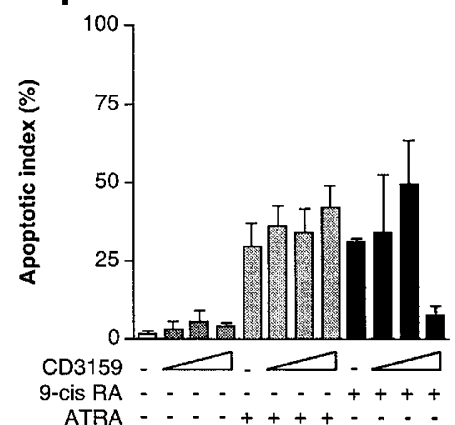

G

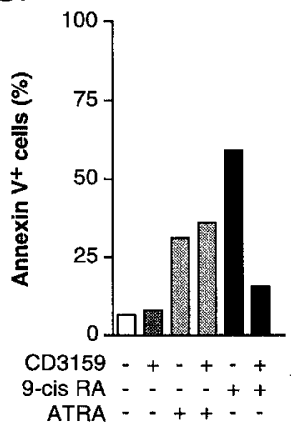

Figure 3 Effect of RAR and RXR antagonists on ATRA- and 9-cis RA-dependent growth arrest, granulocytic maturation, and apoptosis in NB4 cells. NB4 cells were seeded at an initial concentration of $2 \times 10^{5} / \mathrm{ml}$ and treated for 6 days with medium alone (control) or the various compounds, as indicated. ATRA and 9-cis RA were used at $10^{-7} \mathrm{M}$, the RAR antagonist CD3106 at $10^{-5} \mathrm{M}$ and the RXR antagonist CD3159 at $10^{-7} \mathrm{M}, 10^{-6} \mathrm{M}$ and $10^{-5} \mathrm{M}$ (open triangles indicate the three increasing concentrations of the compound; in G, CD3159 was used at $10^{-5} \mathrm{M}$ only). Aliquots of the cultures were withdrawn and subjected to counting following erythrosin staining for the determination of the total number of viable cells ( $\mathbf{A}$ and $\mathbf{D})$, the level NBT-reducing activity (B and $\mathbf{E})$, and the degree of apoptosis, as assessed by DAPI staining ( $\mathbf{C}$ and $\mathbf{F}$ ) or fluorescent annexin $V$ binding $(\mathbf{G})$. Results are the mean \pm S.D. of three separate culture dishes except for the annexin $V$ experiments whose results were obtained on a pool of three dishes. The data are representative of those obtained in at least two experiments 

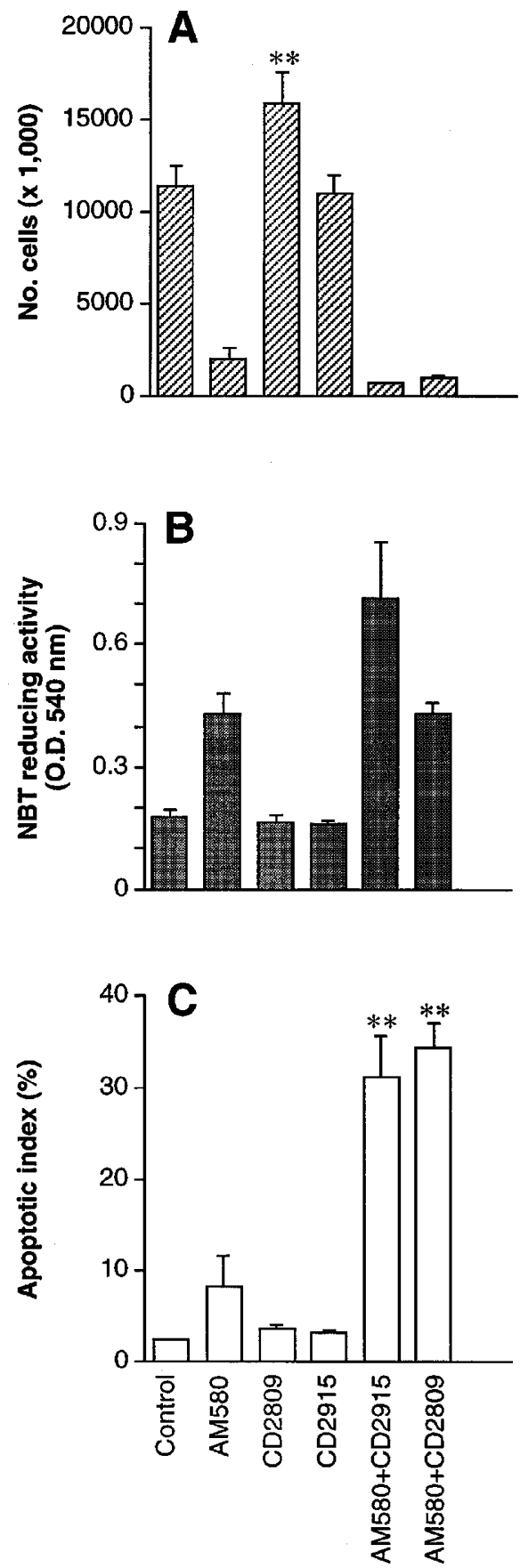

Figure 4 Effect of RXR agonists on AM580-dependent growth inhibition, granulocytic maturation and apoptosis in NB4 cells. NB4 cells were seeded at an initial concentration of $2 \times 10^{5} / \mathrm{ml}$ and treated for 6 days with medium alone (control) or medium containing the PML-RAR $\alpha / R A R \alpha$ agonist AM580 $\left(10^{-8} \mathrm{M}\right)$, the RXR agonists CD2809 and CD2915 $\left(10^{-6} \mathrm{M}\right)$ or combinations between AM580 and CD2809 or CD2915. Aliquots of the cultures were withdrawn and subjected to counting following erythrosin staining for the determination of the total number of viable cells $(\mathbf{A})$, the level of NBT-reducing activity (B), and the degree of apoptosis, following staining with DAPI (C). Results are the mean \pm S.D. of three separate culture dishes and are representative of at least three independent experiments conducted with each compound or combination of compounds. ${ }^{* *}$ Statistically significant relative to AM580 alone according to the Student's $t$-test $(P<0.01)$ activation bands following treatment of NB4 cells with the strong and rapidly-acting apoptogenic retinoid CD437. ${ }^{22}$ Moreover, similar results were observed with commercially available antibodies of different origin.

The ATRA-dependent increase in pro-caspase-1 and pro-caspase-7 proteins is the consequence of increased accumulation of the corresponding mRNA (Figure 6, left panels). In basal conditions, NB4 cells express barely detectable amounts of two transcripts specifically hybridizing with a caspase- 1 cDNA probe (the two mRNA species are evident upon longer exposures of the Northern blots presented). In addition, readily measurable amounts of pro-caspase-7, -8 and -9 are synthesized by undifferentiated NB4 cells. Treatment of cells with ATRA $\left(10^{-6} \mathrm{M}\right)$ results in an upregulation of the two pro-caspase-1 mRNAs which is detectable at day 1 and increases until at least day 4. The rise of pro-caspase-7 is an earlier event than induction of caspase-1 mRNA, as expected on the basis of the results obtained at the protein level. Surprisingly, in spite of no modification of the corresponding proteins, the transcripts coding for caspase-8 and caspase- 9 are upregulated by ATRA. ATRA-dependent accumulation of the transcripts for caspase-1, -7, -8 and -9 is likely to be of transcriptional nature, as it is inhibited by RNA polymerase II inhibitors like actinomycin D (data not shown). Pretreatment of NB4 cells with the protein synthesis inhibitor cycloheximide has no effect on the ATRA-dependent up-regulation of the mRNAs for procaspase-7 and -9 , whereas it completely blocks the surge of the transcripts coding for pro-caspase- 1 and -8 (Figure 6 , right panels). This suggests that, while the genes coding for pro-caspase-7 and -9 may be direct targets for the activity of ATRA, regulation of the genes for procaspase- 1 and -8 is indirect and mediated by the synthesis of ATRA-regulated proteins.

\section{Influence of retinoids on the activation of caspases in NB4 cells}

Following treatment of NB4 cells with ATRA, AM580 and 9cis-RA, Western blot experiments with the majority of caspase-specific antibodies (with the notable exceptions of the caspase-7 antibodies) did not reveal the presence of proteolytic degradation bands resulting from the activation of the various caspase isoenzymes considered. Thus, the state of activation of caspases was studied with a more sensitive method. We used the fluorogenic tetrapeptides YVAD-amc to measure caspase-1, ${ }^{31}$ WEHD-amc for caspase-1, -4 and $-5,{ }^{32,33}$ DEVD-amc for caspase-3-like enzymes (caspase-3, -6 and -7$),{ }^{33}$ VEID-amc for caspase- $6^{34}$ and IETD-amc for caspase-8. ${ }^{33}$

As shown in Figure 7A, detectable and variable background levels of DEVD-amc, VEID-amc and IETDamc hydrolytic activity are present in undifferentiated NB4 cells. In the same experimental conditions, barely detectable amounts of YVAD-amc and WEHD-amc are observed (data not shown). Challenge of NB4 cells for 6 days with various concentrations of ATRA, 9-cis RA and AM580 results in a significant and dose-dependent increase in DEVD-amc, VEID-amc and IETD-amc hydro- 


\section{A}

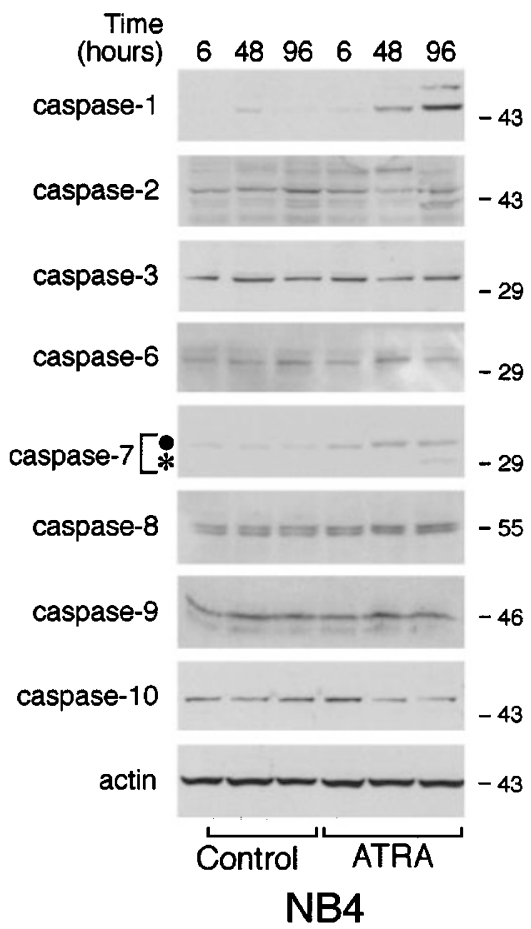

$\begin{array}{llllll}6 & 48 & 96 & 6 & 48 & 96\end{array}$

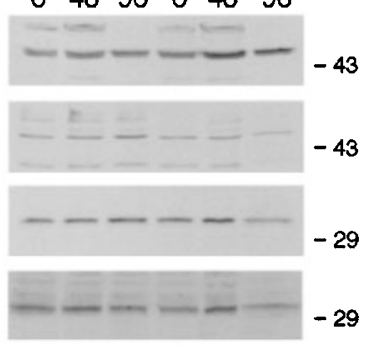

. 4

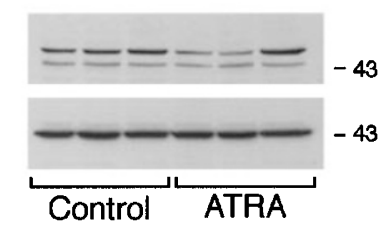

NB4. 306
B

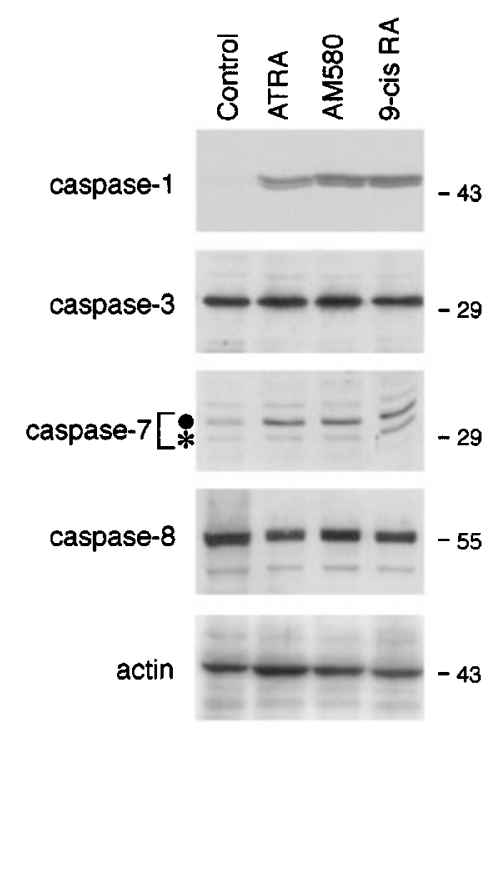

Figure 5 Expression of caspase proteins in retinoid treated NB4 and ATRA-resistant NB4.306 cells. NB4 and NB4.306 cells $\left(2 \times 10^{5} / \mathrm{ml}\right)$ were treated with vehicle alone (Control) and ATRA $\left(10^{-6} \mathrm{M}\right)$, AM580 $\left(10^{-8} \mathrm{M}\right)$ or 9 -cis RA $\left(10^{-6} \mathrm{M}\right)$ for the indicated amount of time $(\mathbf{A})$ or 4 days $(\mathbf{B})$. Aliquots of the NB4 homogenates containing an equivalent amount of protein were subjected to Western blot analysis with antibodies specific for the indicated caspases or for $\beta$-actin. The molecular weight of protein standards is indicated on the right in $\mathrm{kDa}$. The band corresponding to pro-caspase-7 is indicated by a solid dot, whereas the degradation band corresponding to the large subunit of caspase-7 is indicated by an asterisk on the left. The data are representative of those obtained in at least two experiments

lytic activities. The same treatments do not cause an augmentation in the levels of either YVAD-amc or WEHDamc activity (data not shown). The profiles of the dosedependent activation of DEVD-amc, VEID-amc and IETDamc by ATRA and 9-cis are not substantially different from one another in several experiments and show a gradual increase between $10^{-9}$ and $10^{-6} \mathrm{M}$. By contrast, AM580 is a much better activator of DEVD-amc (with a maximal effect at $10^{-8} \mathrm{M}$ ) than of VEID-amc or IETD-amc hydrolytic activity. Activation of caspase-3 or caspase-3 like activity (presumably caspase- 6 and/or -7 ) is further confirmed by the Western blot experiment shown in Figure 7D. PARP contains a DEVD cleavage sequence recognized by caspase-3, -6 and $-7 . .^{33}$ Activation of any of these proteases results in cleavage of the $110 \mathrm{kDa}$ PARP protein and in the appearance of a specific $85 \mathrm{kDa}$ fragment. $^{35}$ In basal conditions, NB4 cells synthesize detectable amounts of the $110 \mathrm{kDa}$ PARP polypeptide which is recognized by the antibody used in these experiments. Treatment of NB4 cells for 6 days with ATRA $\left(10^{-6} \mathrm{M}\right), 9$-cis RA $\left(10^{-6} \mathrm{M}\right)$ or AM580 $\left(10^{-8} \mathrm{M}\right)$ results in the disappearance of the band corresponding to intact PARP and causes the appearance of the corresponding $85 \mathrm{kDa}$ proteolytic fragment. A similar treatment with the non-apoptogenic RXR agonist, CD2809, does not lead to cleavage of PARP.

\section{Role of caspases in the processes of apoptosis triggered by ATRA, 9-cis RA and AM580 in APL cells}

To investigate whether caspases responsible for the hydrolysis of DEVD-amc are involved in the process of apoptosis, we performed three types of experiments.

First, we evaluated whether the time course for the activation of DEVD-amc and IETD-amc is consistent with the process of apoptosis triggered by ATRA. Figure 8 demonstrates that treatment of NB4 cells with ATRA $\left(10^{-6} \mathrm{M}\right)$ results in a linear elevation in the amounts of the caspase activity which is evident from the third day on. Similar kinetics of induction of DEVD-amc hydrolytic activity are observed following treatment of NB4 cells with 9-cis RA and AM580 (data not shown). All this along with the results shown in Figure 1C,D suggests that activation of a caspase-3-like enzyme precedes and/or accompanies the PCD program triggered by ATRA, 9-cis RA and AM580. By contrast, the increase in IETD-amc hydrolytic activity by ATRA, is a late event observed only following 6 days of treatment with the retinoid (data not shown).

Second, we evaluated the effects of RAR and RXR blockade and of RAR and RXR simultaneous activation on the levels of DEVD-amc hydrolytic activity. Incubation of NB4 cells for 6 days with the RAR antagonist CD3106, at 


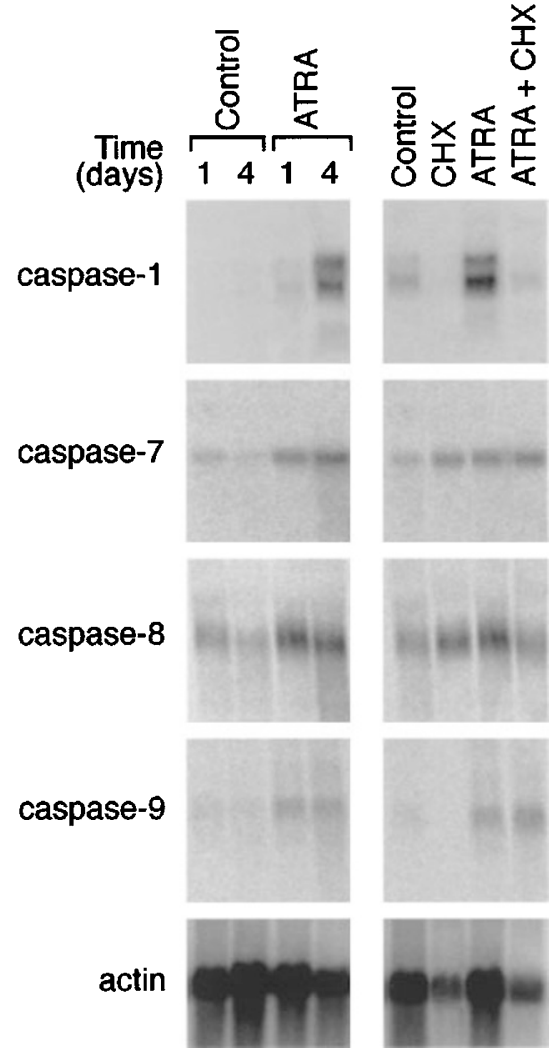

Figure 6 Expression of caspase mRNAs in ATRA treated NB4 cells. Effects of $\mathrm{CHX}$ on mRNA accumulation. NB4 cells $\left(2 \times 10^{5} / \mathrm{ml}\right)$ were treated with medium alone (control) and ATRA $\left(10^{-6} \mathrm{M}\right)$ in the absence or presence of $\mathrm{CHX}(10 \mu \mathrm{g} / \mathrm{ml})$ for the indicated amount of time (left panels) or for $16 \mathrm{~h}$ (right panels). Total RNA was extracted and equivalent amounts of it $(10 \mu \mathrm{g})$ subjected to Northern blot analysis with cDNAs encoding the indicated caspases or actin

$10^{-5}$ and $10^{-6} \mathrm{M}$, completely suppresses the induction of DEVD-amc hydrolytic activity triggered by $10^{-7} \mathrm{M}$ ATRA and $10^{-8} \mathrm{M}$ AM580 (Figure 8B). Similarly, complete inhibition of the 9-cis RA-dependent activation of DEVDamc activity is observed following co-incubation of NB4 cells with optimal concentrations of the RXR antagonist CD3159 $\left(10^{-5} \mathrm{M}\right)$ (Figure $\left.8 \mathrm{C}\right)$. Challenge of NB4 blasts for 6 days with the two RXR agonists CD2809 $\left(10^{-6} \mathrm{M}\right)$ and CD2915 $\left(10^{-6} \mathrm{M}\right)$ does not affect the basal level of DEVDamc hydrolytic activity. However, combination of each of the two retinoids with $\operatorname{AM} 580\left(10^{-8} \mathrm{M}\right)$ causes a synergistic activation of the caspase-dependent enzymatic activity relative to what is observed with the $R A R \alpha$ agonist alone (Figure $8 D$ ). The results with RAR/RXR agonists and antagonists on DEVD-amc activity parallel those on NB4 apoptosis (Figure 3C, F and G).

Third, we studied the influence of the cell-permeable tripeptide caspase inhibitor z-VAD on the apoptogenic program set in motion by cyto-differentiating retinoids. For this purpose, TUNEL assays were performed on NB4 cells grown in the presence or absence of ATRA, AM580 or 9-cis $\mathrm{RA}$ following challenge with $\mathrm{z}-\mathrm{VAD}$ for $24 \mathrm{~h}$ between the fourth and fifth day of treatment (Figure 9A). Approximately $6 \%$ of the NB4 cells show TUNEL positivity in basal conditions, indicating a background level of apoptosis. The proportion of apoptotic cells is slightly decreased upon treatment with z-VAD alone $(50 \mu \mathrm{M})$. Treatment of cells for 5 days with ATRA $\left(10^{-6} \mathrm{M}\right), \operatorname{AM} 580\left(10^{-8} \mathrm{M}\right)$ and 9-cis RA $\left(10^{-6} \mathrm{M}\right)$ causes a significant elevation in the proportion of apoptotic cells. Addition of $z-V A D$ to the culture medium largely prevents the retinoid-dependent increase in the percentage of apoptotic cells. In the same experimental conditions, ATRA-dependent activation of DEVD-amc hydrolytic activity and cleavage of PARP are completely inhibited (Figure 9B). Thus, our results demonstrate that complete inhibition of caspase activity results in a significant albeit incomplete inhibition of the apoptotic process set in motion by retinoids.

To get insight into the factors which may lay upstream of caspase activation in the process of retinoid-induced apoptosis, we evaluated whether ATRA, 9-cis RA and AM580 have any influence on the release of cytochrome $c$ (cyt $c$ ) from the mitochondria. ${ }^{36,37}$ As documented in Figure 10A, treatment of NB4 cells for 4 days with AM580 and 9cis RA is associated with the release of detectable amounts of cyt $c$ into the cytosol. In this particular experiment, the effect of ATRA is less pronounced and detectable levels of cytosolic cyt $c$ are visible only upon longer exposures of the film. A similar phenomenon is not observed if the cells are challenged with the non-apoptogenic RXR agonist CD2809 (data not shown). Consistent with a redistribution of cyt $c$ from the mitochondrial to the cytosolic compartment, a slight but significant decrease in the amounts of the protein associated with the mitochondria is observed following treatment with 9-cis RA or AM580.

The release of cyt $c$ from the mitochondria is, at least partially controlled by members of the Bcl family, such as the anti-apoptotic $\mathrm{Bcl}-2$ and the pro-apoptotic Bax proteins. ${ }^{38}$ In addition, the APL oncogene PML-RAR $\alpha$ is also believed to regulate cell-death, acting as an antiapoptotic determinant. ${ }^{39}$ Thus, we decided to study the influence of ATRA, AM580 and 9-cis RA on the expression of these proteins (Figure 10B). ATRA $\left(10^{-6} \mathrm{M}\right)$, AM580 $\left(10^{-8} \mathrm{M}\right)$ and 9 -cis RA $\left(10^{-6} \mathrm{M}\right)$ treatment of NB4 cells for 4 days produces a clear down-regulation in the levels of $\mathrm{Bcl}-2$ and a parallel up-regulation of Bax, tipping the balance of the two proteins towards a more apoptogenic equilibrium. As expected, treatment of NB4 cells with ATRA results in a selective degradation of PML-RAR $\alpha$. Similar effects are triggered by treatment with optimal cytodifferentiating and apoptogenic concentrations of AM580 and 9-cis RA.

\section{Discussion}

In this study, we report on the effects of ATRA, 9-cis RA and prototypic synthetic retinoids on granulocytic maturation, cell growth and apoptosis of the PML-RAR $\alpha$ positive and APLderived NB4 cell line. In addition, we correlate the three parameters with the expression and the state of activation of various members of the caspase family of proteases.

Among the series of compounds tested, the only retinoids by-passing the maturation block of APL blasts are those capable of activating selectively or non- 

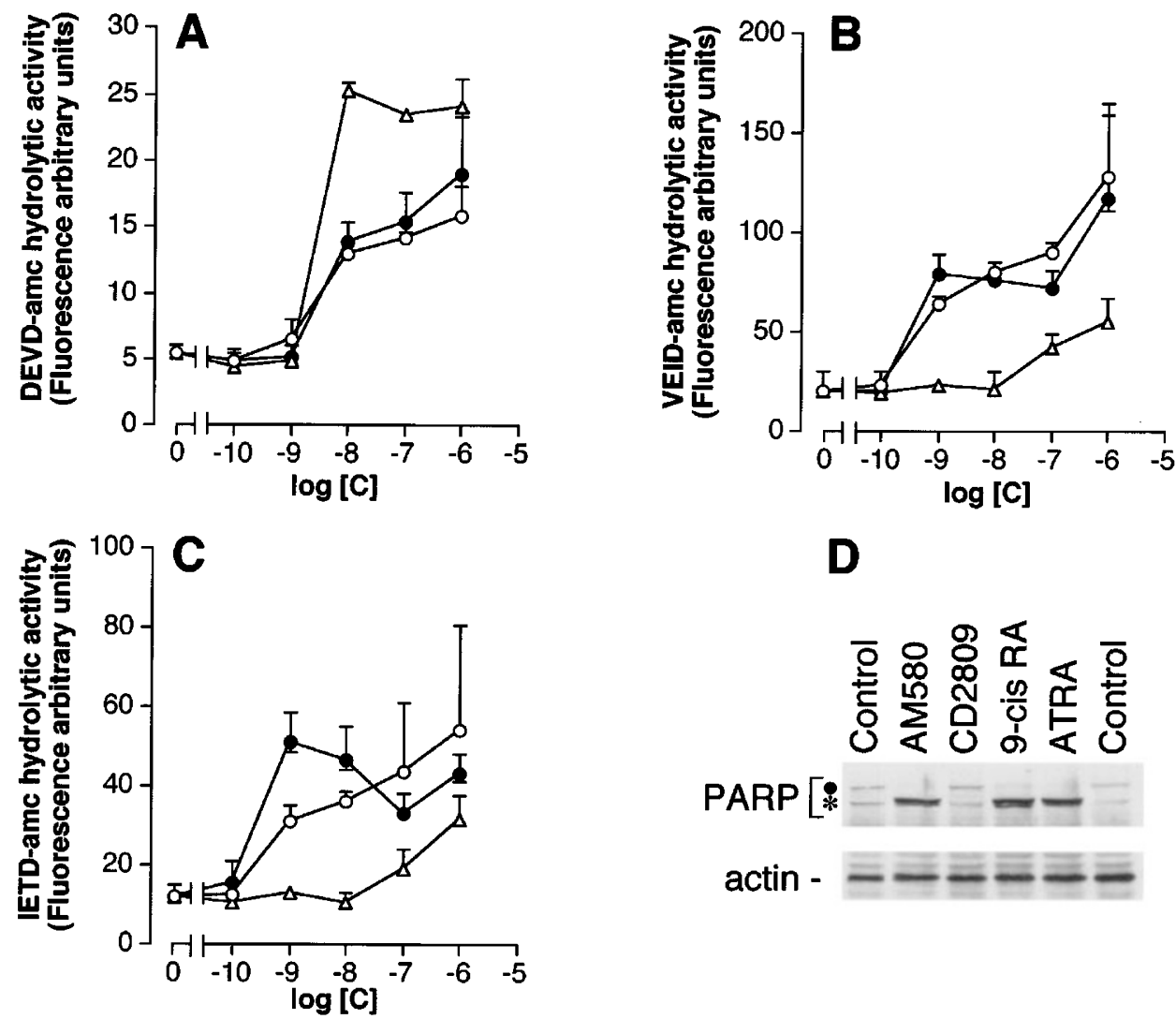

Figure 7 Effect of ATRA, AM580 and 9-cis RA on caspase activation and PARP degradation in NB4 cells. NB4 cells were seeded at an initial concentration of $2 \times 10^{5} / \mathrm{ml}$ and treated for 6 days with vehicle or the indicated concentrations of ATRA (open circles), 9-cis RA (closed circles) or AM580 (open triangles) (A, B and C) or challenged for 4 days with vehicle (control), ATRA $\left(10^{-6} \mathrm{M}\right)$, 9-cis RA $\left(10^{-6} \mathrm{M}\right)$, AM580 $\left(10^{-8} \mathrm{M}\right)$ or CD2809 $\left(10^{-6} \mathrm{M}\right)$ (D). Cell extracts were analyzed for the presence of DEVD-amc (A), VEID-amc (B) and IETD-amc (C) hydrolytic activities, as indicated, to evaluate the level of activation of caspase-3 like enzymes, caspase- 6 and caspase- 8 , respectively. Results are the mean \pm S.D. of three separate culture dishes and are representative of at least two independent experiments conducted with each compound. In (D), equivalent amounts of cell extracts were subjected to Western blot analysis with antibodies specific to PARP or actin. The position of the intact $110 \mathrm{kDa}$ PARP protein and the specific $85 \mathrm{kDa}$ caspase degradation product are indicated by a solid dot and an asterisk, respectively

selectively $\mathrm{RAR} \alpha$ or $\mathrm{PML}-\mathrm{RAR} \alpha$. This, along with the data obtained by RAR antagonistic blockade, corroborates the pivotal role of PML-RAR $\alpha$ and/or RAR $\alpha$ in the process of granulocytic maturation. ${ }^{12}$ Selective activation of RAR $\alpha$ / PML-RAR $\alpha$ is also necessary and sufficient to cause growth arrest of NB4 cells, though this is not the sole mechanism by which the APL blast can be rendered quiescent by retinoids. In fact an anti-proliferative effect, which cannot be explained by trans-activation of RAR $\alpha$ l $\mathrm{PML}-\mathrm{RAR} \alpha$, is observed in the presence of high concentrations of the RAR $\beta$ agonist CD2019 and the RXR agonist CD2915. More importantly, the growth inhibitory action of the 9-cis RA is dependent on RXR homodimer activation, as evidenced by the data obtained with the RXR antagonist CD3159. Surprisingly, ${ }^{40}$ the anti-AP1 compound CD2409, is totally ineffective in causing growth inhibition of NB4 cells. Retinoid-dependent growth inhibition and cytodifferentiation are followed by a slow process of apoptosis which proceeds asynchronously, since, at any given time, it involves a low proportion of cells showing signs of PCD. While there is general agreement between the strength by which $\mathrm{RAR} \alpha / \mathrm{PML}-\mathrm{RAR} \alpha$ activating retinoids induce growth arrest and their ability to determine granulocytic maturation, suggesting tight linkage between the two phenomena, ${ }^{41}$ apoptosis is not simply the consequence of granulocytic maturation and generation of cells that resemble short-lived neutrophils, at least as judged by the relative apoptogenic and cyto-differentiating potential of ATRA, AM580 and 9-cis RA. Although, again, PML-RAR $\alpha$ and/or RAR $\alpha$ activation is sufficient to trigger apoptosis, the process can be modulated by RXR activation. In fact, RXR antagonistic blockade suppresses the apoptogenic response of NB4 cells to 9-cis RA. In addition, stimulation of this type of receptors enhances the apoptogenic potential of the RAR $\alpha$ selective agonist AM580.

Retinoids have dramatic effects on the level of expression of the apoptosis-related proteases known as caspases. Caspases can be grouped into three main categories according to their involvement in cytokine maturation (e.g. caspase-1, -4 and -5), the execution phase of apoptosis (caspase-3, -6 and -7) or the early steps of apoptotic signaling (caspase-8, -9, -10). Caspases are constitutively present as zymogens and require specific proteolytic cleavage to be converted into catalytically active 

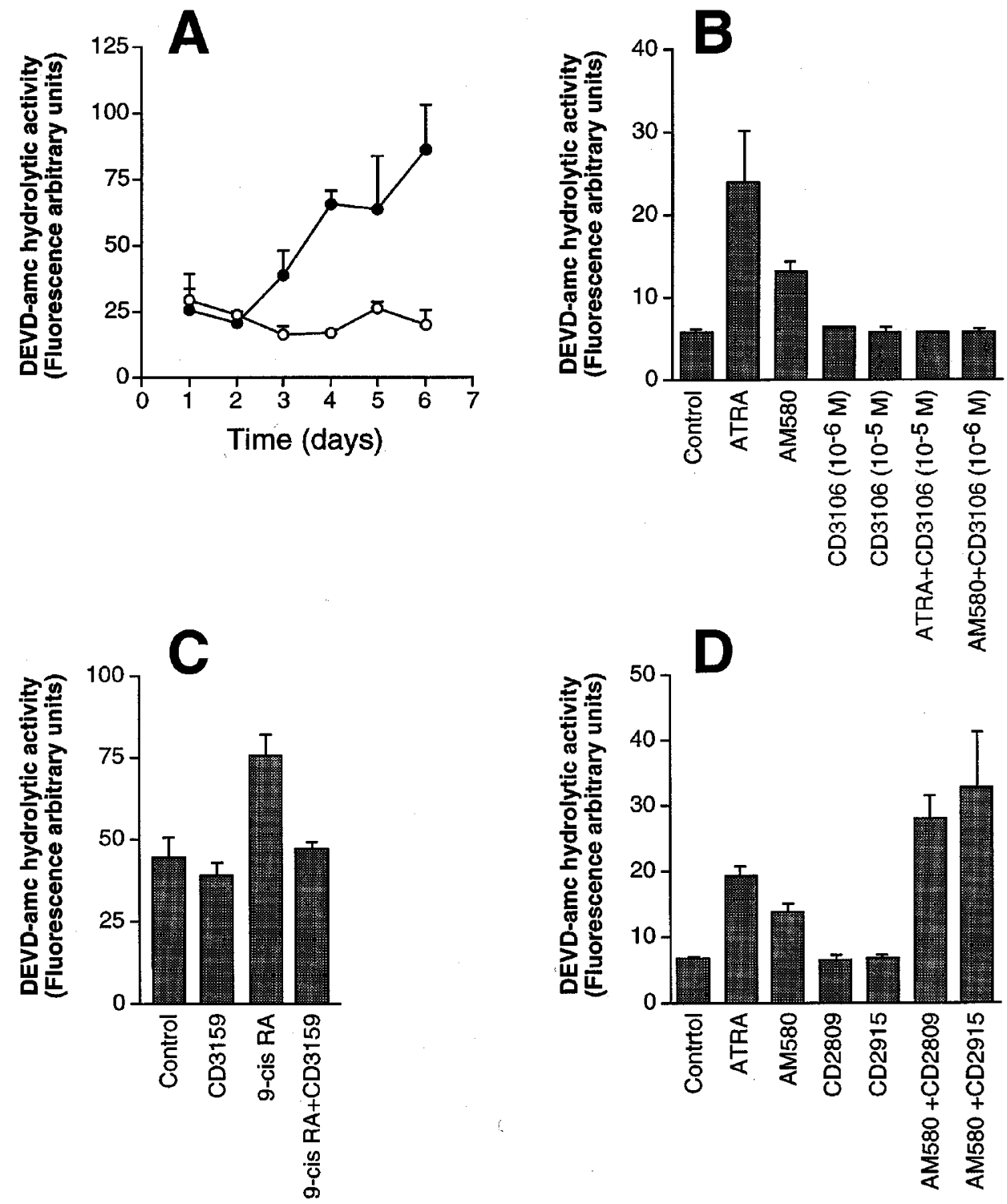

Figure 8 DEVD-amc hydrolytic activity in NB4 cells: time course of ATRA-dependent induction and effects of RAR and RXR agonists or antagonists on ATRA, AM580 and 9-cis RA stimulation. NB4 cells were seeded at an initial concentration of $2 \times 10^{5} / \mathrm{ml}$ and treated as follows: (A) with vehicle (open circles) or ATRA at $10^{-6} \mathrm{M}$ (solid circles) for the indicated amount of time; (B) with vehicle (control), ATRA $\left(10^{-7} \mathrm{M}\right)$ or AM580 $\left(10^{-8} \mathrm{M}\right)$ and the indicated concentrations of CD3106 for 6 days; (C) with vehicle (control), 9-cis RA $\left(10^{-7} \mathrm{M}\right)$, CD3159 $\left(10^{-5} \mathrm{M}\right)$ or the combination of the two compounds; (D) with vehicle (control), ATRA (10 $\left.{ }^{-7} \mathrm{M}\right)$ or AM580 $\left(10^{-8} \mathrm{M}\right)$, CD2809 $\left(10^{-6} \mathrm{M}\right), \mathrm{CD} 2915\left(10^{-6} \mathrm{M}\right)$ or combinations between AM580 and CD2809 or CD2915. Cell extracts were analyzed for the presence of DEVD-amc hydrolytic activity to evaluate the level of activation of caspase-3 like enzymes. Results are the mean \pm S.D. of three separate culture dishes and are representative of at least two independent experiments conducted with each compound or combination of compounds

heterodimers. Treatment of NB4 cells with ATRA upregulates the expression of the genes coding for pro-caspase-1, $-7,-8$ and -9 . Upregulation of pro-caspase genes is probably not a peculiarity of APL promyelocytes but rather a physiological event associated with maturation of normal myeloid precursors along the granulocytic pathway, as indicated by the data obtained in the HL-60 cell line. ${ }^{42}$ The phenomenon is likely to be transcriptional in nature, since it is completely inhibited by RNA polymerase II inhibitors. In the case of pro-caspase-7 and -9, ATRA-dependent mRNA induction does not require de novo protein synthesis, suggesting that the corresponding genes are primary targets for the activity of ATRA and other retinoids. By contrast, upregulation of the genes coding for pro-caspase1 and -9 requires the mediation of transcriptional factors whose synthesis is retinoid-regulated. Induction of members of this family of proteases is controlled not only at the transcriptional but also at the translational or posttranslational level. In fact, upregulation of pro-caspase-1 and -8 mRNAs is followed by accumulation of the corresponding protein, whereas a similar effect is not observed in the case of pro-caspase- 8 and -9 .

Retinoid-induced maturation of NB4 cells results not only in induction of pro-caspase-1 and pro-caspase-7, but also 


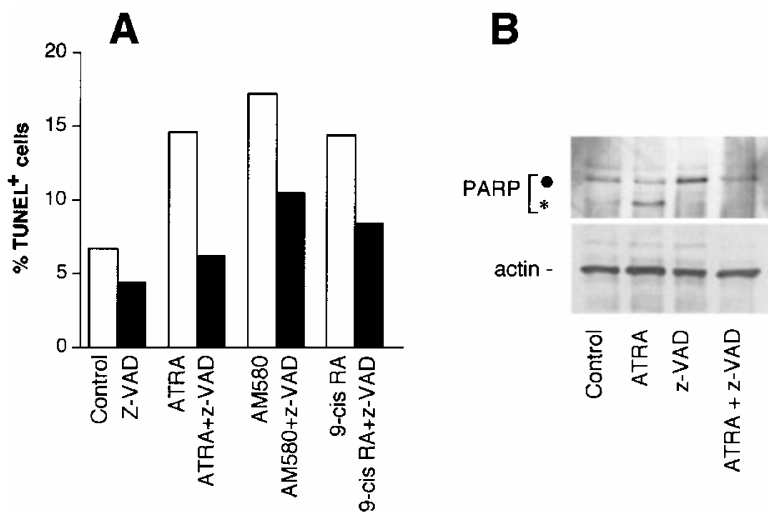

Figure 9 Effect of the caspase inhibitor z-VAD on apoptosis induced by ATRA, 9-cis RA and AM580. NB4 cells were seeded at an initial concentration of $2 \times 10^{5} / \mathrm{ml}$ and treated for 4 days with vehicle (control), ATRA $\left(10^{-6} \mathrm{M}\right), 9$ cis-RA $\left(10^{-6} \mathrm{M}\right)$ and $\mathrm{AM} 580\left(10^{-8} \mathrm{M}\right)$. At the fourth day, cells were treated with vehicle alone (DMSO) or z-VAD $(50 \mu \mathrm{M})$ twice every $12 \mathrm{~h}$ for the successive $24 \mathrm{~h}$. Cells were harvested and subjected to the TUNEL assay by flow cytometry (A) or to Western blot analysis with specific anti-PARP or actin antibodies (B). The position of the intact $110 \mathrm{kDa}$ PARP protein and the specific $85 \mathrm{kDa}$ caspase degradation product are indicated by a solid dot and an asterisk, respectively

A

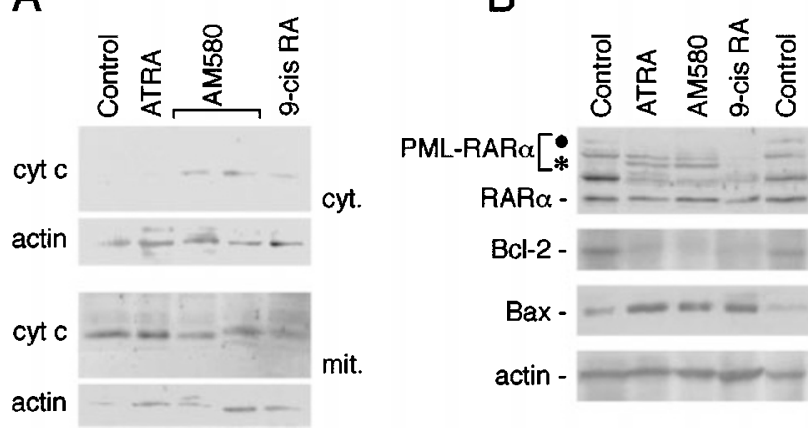

protein band, which is likely to represent the small subunit of the active caspase heterodimer (M Giannǐ;, I Ponzanelli and $E$ Garattini, unpublished results). Second, ATRA and cyto-differentiating retinoids caused the appearance of a $29 \mathrm{kDa}$ caspase-7 degradation band corresponding to the large subunit of the catalytically active heterodimer. Third, the process of apoptosis set in motion by ATRA and other cyto-differentiating retinoids is accompanied by cleavage of PARP, a protein substrate not only of effector caspase-3 but also of effector caspase- 6 and -7. At present, we do not have any direct Western blot evidence of caspase-3 or caspase- 9 activation. Thus, the increase in DEVD-amc hydrolytic activity observed following treatment of NB4 cells with retinoids is probably the consequence of caspase- 6 and -7 , rather than caspase- 3 activation. We are also inclined to rule out activation of caspase-1, $-4,-5$ and -10 during retinoid-induced PCD. The contention is based on the lack of detectable degradation of caspase-1, -4 and -10 upon Western blot analysis, and by the lack of increased YVAD-amc (caspase-1 substrate) and WEHD-amc (caspase-1, -4 and -5 substrate) hydrolytic activity. Regardless of the particular isoenzyme(s) involved, caspase activation has an important role in the process of apoptosis triggered by ATRA, 9-cis RA and AM580 in APL cells, as inhibition of this class of proteases leads to strong attenuation of PCD.

Release of cyt $c$ from the mitochondrial compartment is known to be a potent apoptogenic stimulus. ${ }^{36-38}$ Formation of a cytosolic complex consisting of cyt $c$, Apaf-1 and ATP or dATP leads to activation of pro-caspase-9 and subsequently of executioner caspases. Relocalization of cyt- $c$ is triggered in both a caspase-8-independent ${ }^{43}$ and a caspase-8-dependent fashion. ${ }^{44}$ In addition, the flux of cyt $c$ from the inner mitochondrial compartment outward into the cytosol is regulated positively or negatively by members of the Bcl-2 family of proteins. ${ }^{38}$ In NB4 cells, 9-cis RA and AM580 are all capable of causing leakage of cyt $c$ from the mitochondria. The time course of this precedes or accompanies the activation of caspase isoenzymes ( $M$ Gianni, I Ponzanelli and E Garattini, unpublished results). Cyt $c$ relocalization is associated with a downregulation in the expression of the anti-apoptotic $\mathrm{Bcl}-2$ protein and an upregulation of the pro-apoptotic Bax protein. ${ }^{38}$ Therefore, the apoptogenic action of retinoids in APL cells may include the following ordered steps: alteration of the Bcl2/Bax ratio, release of cyt $c$ from the mitochondria and activation of executioner caspases. The retinoid dependent-degradation $^{45}$ of the anti-apoptotic PML-RAR $\alpha$ oncogene ${ }^{39}$ may represent the primary driving force for the entire process. In this scenario, caspase- 9 activation should play the role of the initiating caspase, (although, as already discussed, evidence for this is lacking) whereas caspase- 6 and caspase-7 are likely to play a relevant role as executioner caspases. At present, it is difficult to establish where activation of pro-caspase- 8 fits in this picture. It is possible that activation of this isoenzyme drives cyt $c$ release from the mitochondria, perhaps through cleavage of Bid, ${ }^{55}$ although it is more likely that conversion of pro-caspase-8 into the active enzyme is just a secondary event.

In conclusion, the data contained in this article are helpful in shedding light into the relationship among the 
processes of granulocytic maturation, growth inhibition and apoptosis which are the results of APL cells treatment with ATRA and other retinoids. They indicate that different retinoids influence the three processes in different ways. Furthermore, our data demonstrate that retinoids modulate caspase proteins, directly or indirectly and at various levels. All this may have important clinical implications in devising new and more effective strategies in the treatment of APL.

\section{Materials and Methods}

\section{Chemicals}

The RAR $\alpha$ agonist AM580, ${ }^{10}$ the RAR $\beta$ agonist CD2019, ${ }^{28}$ the RXR agonists CD2809 and CD2915, ${ }^{29}$ the anti-AP1 retinoid CD2409, the pan-RAR reverse agonist CD3106 (AGN193109) ${ }^{46}$ and the pan-RXR antagonist CD3159 (LG100754) ${ }^{30}$ were synthesized by CIRDGalderma Research and Development (Sophia Antipolis, France). The pan-RAR agonist TTNPB ${ }^{27}$ was a kind gift from Dr. Klaus (Hoffmann-la Roche, Basel, Switzerland). ATRA and 9-cis RA were from Sigma (St Louis, MO, USA). Stock solutions of retinoids in dimethylsulfoxide $\left(10^{-2} \mathrm{M}\right)$ were kept in aliquots at $-80^{\circ} \mathrm{C}$ protected from the light until use.

\section{Cell culture and treatment}

The NB4 cell line 47 (Dr. Michel Lanotte, Hopital Saint Louis, Paris, France), and the ATRA-resistant NB4.306 clone ${ }^{23}$ (Dr. Carlo PasseriniGambacorti, Istituto Nazionale dei Tumori di Milano, Italy) were cultured in the presence of RPMI-1640 containing $10 \%$ FCS. The cell lines were free from mycoplasma contamination, as assessed by staining with Hoechst 33258. To prevent apoptosis, control cultures were kept in the logarithmic phase of growth $\left(3-6 \times 10^{-5}\right.$ cells $\left./ \mathrm{ml}\right)$ by dilution in fresh medium every 2 days. Parallel retinoid-treated cultures were similarly diluted in drug-containing medium to keep the cell density between (3$6 \times 10^{-5} \mathrm{cells} / \mathrm{ml}$ ). All the experiments described were performed using heat-inactivated serum, which, in our experimental conditions, is equivalent to retinoid-free charcoal treated serum.

\section{Determination of cell viability, apoptosis and DEVD-amc hydrolytic activity}

Cell viability was determined by counting the percentage of red/ white cells in Burker chambers following staining with erythrosin (Sigma). For the determination of the apoptotic index (percentage of cells with fragmented nuclei), cells were fixed under methanol and stained with 4'-6-diamidine-2-phenylindole (DAPI), as described. ${ }^{22}$ The TUNEL (Tdt-mediated dUTP nick end labeling) assay was performed with a commercially available kit according to the instructions of the manufacturer (In situ cell detection kit, Fluorescein, Boehringer Mannheim, Germany). Stained cells were analyzed by flow cytometry using the FacSort system (Becton and Dickinson, Sunnyvale, CA, USA). DNA fragmentation was determined according to the Diphenylamine assay, as already described. ${ }^{22}$ Fragmentation was calculated as the percentage of total DNA (supernatant and pellet) recovered as low-molecularweight DNA in the supernatant. Externalization of the plasma membrane phosphatidylserine pool was determined by measuring the binding of fluorescein-conjugated annexin $\mathrm{V}$ by bi-parametric flow cytometry following counterstaining with propidium iodide. Staining with annexin $\mathrm{V}$ was performed with a commercially available kit. Flow cytometric analysis was performed using the FacSort system (Becton and Dickinson).

\section{Activation of caspase isoenzymes and intracellular cytochrome $c$ redistribution}

Activation of caspase isoenzymes was measured with the use of the specific fluorogenic substrates: YVAD-amc (caspase-1), WEHD-amc (caspase-1, -4 and -5), DEVD-amc (caspase-3), VEID-amc (caspase6 ) and IETD-amc (caspase-8), as detailed elsewhere, ${ }^{22}$ following normalization for the protein content of the experimental samples by the Bradford method. ${ }^{48}$ All the fluorogenic compounds were from the Peptide Institute Inc. (Osaka, Japan).

For the determination of cytochrome $c$ intracellular redistribution, cytosolic and mitochondrial fractions from NB4 cells were obtained as described. ${ }^{22}$ The two subcellular fractions were stored at $-80^{\circ} \mathrm{C}$ until assay by Western blot analysis.

\section{Western blot analysis}

For Western blot analysis, total cellular extracts from NB4 (approximately $3 \times 10^{-6}$ cells) were prepared as described. ${ }^{22}$ Aliquots of the extracts were fractionated by electrophoresis on $10 \%$ SDS acrylamide gel and electrotransferred to nitrocellulose membranes, which were challenged with antibodies raised against peptides corresponding to caspase-1 (antibody p20 (c-15), Santacruz), caspase-2 (antibody H-19, Santacruz), caspase-3 (antibody E-8, Santacruz), caspase-6 (antibody B93-4, aa 271-285, Pharmingen), caspase-7 (antibody B94-1, aa 25-42, Pharmingen), caspase-8 (antibody Casp8-p18, Biomedia), caspase-9 (antibody B40, aa 364405, Pharmingen), caspase-10 (antibody p20 ( $\mathrm{H}-131$, Santacruz), poly ADP ribose polymerase (PARP) (antibody C-2-10, Biomol), cyt $c$ (antibody 7H8.2C12, aa 93-104, Pharmingen) and Actin (antibody I19, Santacruz). Bands were visualized with a chemiluminescencebased procedure using the ECL detection kit (Amersham, Little Chalfont, UK).

\section{RNA extraction and Northern blot analysis}

Total RNA was extracted from NB4 cells as already described. ${ }^{26}$ Northern blot analysis was performed on nylon filter membranes (NEN, Boston, MA, USA), as reported, ${ }^{26}$ using CDNA probes for caspase-1, $-7,-8,-9$ (a kind gift of Dr. Marta Muzio, USA ${ }^{19}$ and $\beta$-actin. ${ }^{26}$ Imaging and quantitation of Northern blots was performed with the STORM 460 phosphoimager (Amersham-Pharmacia Instrumentation, Little Chalfont, UK).

\section{Acknowledgements}

This work was financially supported by grants to $E$ Garattini from the Associazione Italiana per la Ricerca control il Cancro (AIRC) and from the "Istituto Superiore di Sanità". I Ponzanelli is the recipient of a fellowship from "La Via di Natale". We are grateful to Dr. Eugenio Erba for helping us in the experiments involving flow cytometry, to Prof. Silvio Garattini and Dr. Mario Salmona for critical reading of the manuscript.

\section{References}

1. Gudas LJ, Sporn MB and Roberts AB (1994) CellularBiology and Biochemistry of Retinoids. In: The Retinoids: Biology, Biochemistry and Medicine. Sporn MB, Roberts AB and Goodman DS (eds). New York: Raven Press. pp. 443-520 
2. Warrell Jr RP, Frankel SR, Miller Jr WJ, Scheinberg DA, Itri LM, Hittelman WN, Vyas R, Andreeff M, Tafuri A, Jakubowski A, Gabrilove J, Gordon MS and Dmitrovsky E (1991) Differentiation therapy of acute promyelocytic leukemia with tretinoin (all-trans retinoic acid). N. Engl. J. Med. 324: 1385-1393

3. Kantarjian HM, Keating MJ, Walters RS, Estey EH, McCredie KB, Smith TL, Dalton Jr WT, Cork A, Trujillo JM and Freireich EJ (1986) Acute promyelocytic leukemia. M.D. Anderson hospital experience. Am. J. Med. 80: 789-797

4. Elliott S, Taylor K, White S, Rodwell R, Marlton P, Meagher D, Wiley J, Taylor D, Wright $S$ and Timms P (1992) Proof of differentiative mode of action of all-trans retinoic acid in acute promyelocytic leukemia using $\mathrm{X}$-linked clonal analysis. Blood 79: 1916-1919

5. Bruel A, Karsenty E, Schmid M, McDonnell TJ and Lanotte M (1997) Altered sensitivity to retinoid-induced apoptosis associated with changes in the subcellular distribution of Bcl-2. Exp. Cell. Res. 233: 281-287

6. Taimi M and Breitman TR (1997) Growth, differentiation, and death of retinoic acid-treated human acute promyelocytic leukemia NB4 cells. Exp. Cell. Res. 230: $69-75$

7. Chen JY, Clifford J, Zusi C, Starrett J, Tortolani D, Ostrowski J, Reczek PR, Chambon P and Gronemeyer H (1996) Two distinct actions of retinoid-receptor ligands. Nature 382: 819-822

8. Bruel A, Benoit G, De Nay D, Brown S and Lanotte M (1995) Distinct apoptotic responses in maturation sensitive and resistant $t(15 ; 17)$ acute promyelocytic leukemia NB4 cells. 9-cis retinoic acid induces apoptosis independent of maturation and Bcl-2 expression. Leukemia 9: 1173-1184

9. Gallagher R, Collins S, Trujillo J, McCredie K, Ahearn M, Tsai S, Metzgar R, Aulakh G, Ting R, Ruscetti F and Gallor R (1979) Characterization of the continuous, differentiating myeloid cell line (HL-60) from a patient with acute promyelocytic leukemia. Blood 54: 713-733

10. Gianni' M, Li Calzi M, Terao M, Caccia S, Guiso G, Barbui T, Rambaldi A and Garrattini E (1996) AM580, a stable benzoic derivative of all-trans retinoic acid, is more active than the parent compound in activating the acute promyelocytic luekemia-specific aberrant form of RAR and in inducing granulocytic maturation of APL cells. Blood 87: 1520-1531

11. Nagy L, Thomazy VA, Shipley GL, Fesus L, Lamph W, Heyman RA, Chandraratna RA and Davies PJ (1995) Activation of retinoid X receptors induces apoptosis in HL-60 cell lines. Mol. Cell. Biol. 15: 3540-3551

12. Melnick A and Licht JD (1999) Deconstructing a disease: RARalpha, its fusion partners, and their roles in the pathogenesis of acute promyelocytic leukemia. Blood 93: 3167-3215

13. Wolf BB and Green DR (1999) Suicidal tendencies: apoptotic cell death by caspase family proteinases. J. Biol. Chem. 274: 20049-20052

14. Porter AG and Janicke RU (1999) Emerging roles of caspase-3 in apoptosis. Cell Death Differ. 6: 99-104

15. Nunez G, Benedict MA, Hu Y and Inohara N (1998) Caspases: the proteases of the apoptotic pathway. Oncogene 17: 3237-3245

16. Brancolini C and Schneider C (1997) Cut and die: proteolytic cascades regulating apoptosis. Adv. Clin. Path. 1:177-189

17. Wilson MR (1998) Apoptosis: unmasking the executioner. Cell Death Differ. 5: $646-652$

18. Muzio M, Chinnaiyan AM, Kischkel FC, O'RourkeK, Shevchenko A, Ni J, Scaffidi C, Bretz JD, Zhang M, Gentz R, Mann M, Krammer PH, Peter ME and Dixit V (1996) FLICE, a novel FADD-homologous ICE/CED-3-like protease, is recruited to the CD95 (Fas/APO-1) death-inducing signaling complex. Cell 85: 817-827

19. Muzio M, Salvesen GS and Dixit VM (1997) FLICE induced apoptosis in a cellfree system. Cleavage of caspase zymogens. J. Biol. Chem. 272: 2952-2956

20. Gross A, Yin XM, Wang K, Wei MC, Jockel J, Milliman C, Erdjument-Bromage H, Tempst $P$ and Korsmeyer SJ (1999) Caspase cleaved BID targets mitochondria and is required for cytochrome $c$ release, while $B C L-X L$ prevents this release but not tumor necrosis factor-R1/Fas death. J. Biol. Chem. 274: 1156-1163

21. Nervi C, Ferrara FF, Fanelli M, Rippo MR, Tomassini B, Ferrucci PF, Ruthardt M, Gelmetti V, Gambacorti-Passerini C, Diverio D, Grignani F, Pelicci PG and Testi R (1998) Caspases mediate retinoic acid-induced degradation of the acute promyelocytic leukemia PML/RARalpha fusion protein. Blood 92: 2244-2251

22. Luca Mologni, Isabella Ponzanelli, Filippo Bresciani, Gabriele Sardiello, Daniele Bergamaschi, Maurizio Gianni', Uwe Reichert, Alessandro Rambaldi, Mineko Terao and Enrico Garattini (1999) The novel synthetic retinoid 6-[3-adamantyl-4hydroxyphenyl]-2-naphtalene carboxylic acid (CD437) causes apoptosis in acute promyelocytic leukemia cells through rapid activation of caspases. Blood 93: $1045-1061$
23. Dermime S, Grignani F, Clerici M, Nervi C, Sozzi G, Talamo GP, Marchesi E, Formelli F, Parmiani G, Pelicci PG and Gambacorti-Passerini C (1993) Occurrence of resistance to retinoic acid in the acute promyelocytic leukemia cell line NB4 is associated with altered expression of the pml/RAR alpha protein. Blood 82: 1573-1577

24. Mangelsorf DJ, Ong ES, Dyck JA and Evans RM (1990) Nuclear recepotor that identifies a novel retinoic acid response pathway. Nature 345: 224-229

25. Heyman RA, Mangelsdorf DJ, Dyck JA, Stein RB, Eichele G, Evans RM and Thaller C (1992) 9-cis retinoic acid is a high affinity ligand for the retinoid $X$ receptor. Cell 68: 397-394

26. Gianni' M, Terao M, Zanotta S, Barbui T, Rambaldi A and Garattini E (1994) Retinoic acid and granulocyte-colony stimulating factor sinergistically induce leukocyte alkaline phosphatase in acute promyelocytic leukemia cells. Blood 83 : $1909-1921$

27. Strickland S, Breitman TR, Frickel F, Nurrenbach A, Hadicke E and Sporn MB (1983) Structure-activity relationships of a new series of retinoidal benzoic acid derivatives as measured by induction of differentiation of murine $\mathrm{Fg}$ teratocarcinoma cells and human $\mathrm{HL}-60$ promyelocytic leukemia cells. Cancer Res. 43: 5268-5272

28. Gianni M, Zanotta S, Terao M, Garattini S and Garattini E (1993) Effects of synthetic retinoids and retinoic acid isomers on the expression of alkaline phosphatase in F9 teratocarcinoma cells. Biochem. Biophys. Res. Commun. 196: $252-259$

29. Sorensen S, Solvsten H, Politi Y and Kragballe K (1997) Effects of vitamin D3 on keratinocyte proliferation and differentiation in vitro: modulation by ligands for retinoic acid and retinoid X receptors. Skin Pharmacol 10: 144-152

30. Lala DS, Mukherjee R, Schulman IG, Koch SS, Dardashti LJ, Nadzan AM, Croston GE, Evans RM and Heyman RA (1996) Activation of specific RXR heterodimers by an antagonist of RXR homodimers. Nature 383: 450-453

31. Schumann RR, Belka C, Reuter D, Lamping N, Kirschning CJ, Weber JR and Pfeil D (1998) Lipopolysaccharide activates caspase-1 (interleukin-1-converting enzyme) in cultured monocytic and endothelial cells. Blood 91: 577-584

32. Rano TA, Timkey T, Peterson EP, Rotonda J, Nicolson DW, Becker JW, Chapman KT and Thornberry NA (1997) A combinatorial approach for determining protease specificities: application to interleukin-1beta converting enzyme (ICE). Chem. Biol. 4: 149-155

33. Thornberry NA, Rano TA, Peterson EP, Rasper DM, Timkey T, Garcia-Calvo M, Houtzager VM, Nordstrom PA, Roy S, Vaillancourt JP, Chapman KT and Nicholson D (1997) A combinatorial approach defines specificities of members of the caspase family and granzyme B. Functional relationships established for key mediators of apoptosis. J. Biol. Chem. 272: 17907-17911

34. Takahashi A, Goldschmidt-Clermont PJ, Alnemri ES, Fernandes-Alnemri T, Yoshizawa-Kumagaya K, Nakajima K, Sasada M, Poirier GG and Earnshaw WC (1997) Inhibition of ICE-related proteases (caspases) and nuclear apoptosis by phenylarsine oxide. Exp. Cell Res. 231: 123-131

35. Rosen A and Casciola-Rosen L (1997) Macromolecular substrates for the ICElike proteases during apoptosis. J. Cell Biochem. 64: 50-54

36. Green DR and Reed JC (1998) Mitochondria and apoptosis. Science 281 $1309-1312$

37. Qin H, Srinivasula SM, Wu G, Fernandes-Alnemri T, Alnembri ES and Shi $Y$ (1999) Structural basis of procaspase-9 recruitment by the apoptotic proteaseactivating factor 1. Nature 399: 549-557

38. Gross A, McDonnell JM and Korsmeyer SJ (1999) BCL-2 family members and the mitochondria in apoptosis. Genes Dev 13: 1899-1911

39. Rogaia D, Grignani F, Grignani F, Nicoletti I and Pelicci PG (1995) The acute promyelocytic leukemia-specific PML/RAR alpha fusion protein reduces the frequency of commitment to apoptosis upon growth factor deprivation of GMCSF-dependent myeloid cells. Leukemia 9: 1467-1472

40. van der Burg B, Slager-Davidov R, van der Leede BM, de Laat SW and van der Saag PT (1995) Differential regulation of AP1 activity by retinoic acid in hormonedependent and -independent breast cancer cells. Mol. Cell Endocrinol. 112: $143-152$

41. Casini T and Pelicci PG (1999) A function of p21 during promyelocytic leukemia cell differentiation independent of CDK inhibition and cell cycle arrest. Oncogene 18: $3235-3243$

42. Watson RW, Rotstein OD, Parodo J, Bitar R, Hackam D and Marshall JC (1997) Granulocytic differentiation of $\mathrm{HL}-60$ cells results in spontaneous apoptosis mediated by increased caspase expression. FEBS Lett. 412: 603-609 
43. Tepper AD, de Vries E, van Blitterswijk WJ and Borst J (1999) Ordering of ceramide formation, caspase activation, and mitochondrial changes during CD95- and DNA damage-induced apoptosis. J. Clin. Invest. 103: 971-978

44. LiH, Zhu H, Xu CJ and Yuan J (1998) Cleavage of BID by caspase 8 mediates the mitochondrial damage in the Fas pathway of apoptosis. Cell 94: 491-501

45. Yoshida H, Kitamura K, Tanaka K, Omura S, Miyazaki T, Hachiya T, Ohno Rand Naoe T (1996) Accelerated degradation of PML-retinoic acid receptor alpha (PML-RARA) oncoprotein by all-trans-retinoic acid in acute promyelocytic leukemia: possible role of the proteasome pathway. Cancer Res. 56: 29452948
46. Agarwal C, Chandraratna RA, Johnson AT, Rorke EA and Eckert RL (1996) AGN193109 is a highly effective antagonist of retinoid action in human ectocervical epithelial cells. J. Biol. Chem. 271: 12209-12212

47. Lanotte M, Martin-Thouvenin V, Najman S, Balerini P, Valensi F and Berger R (1991) NB4, a maturation inducible cell line with $\mathrm{t}(15 ; 17)$ marker isolated from a human acute promyelocytic leukemia (M3). Blood 77: 1080-1086

48. Bradford MM (1976) A rapid and sensitive method for the quantitation of microgram quantities of protein utilizing the principle of protein-dye binding. Anal. Biochem. 72: 248-254 